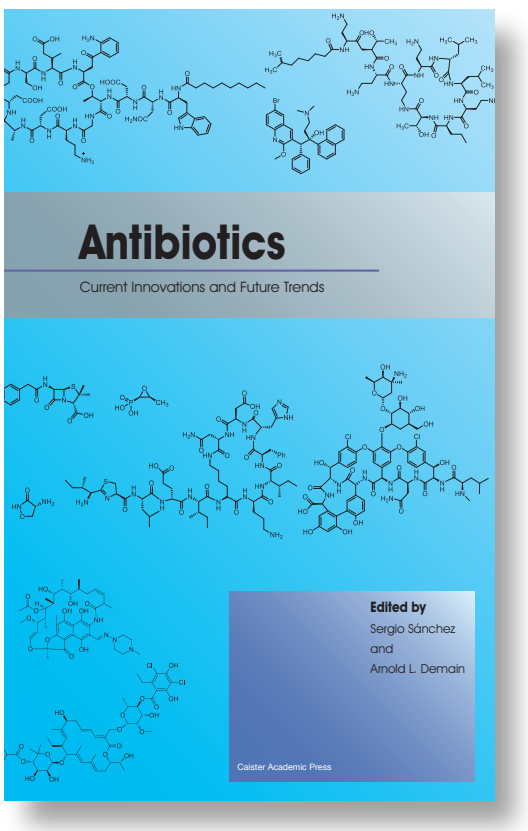

\title{
Antibiotics
}

\section{Current Innovations and Future Trends}

Edited by: Sergio Sánchez and Arnold L. Demain

Universidad Nacional Autónoma de México, México and RISE, Drew University, Madison, USA; respectively

C. $480 \mathrm{pp}$

Hardback: January 2015. ISBN 978-1-908230-54-6£180, \$360

Ebook: January 2015. ISBN 978-1-908230-55-3 £180, \$360

Available December 2014

The 'golden age' for antibiotic discovery, from 1940 until the early 1970s, ushered in a new era in humanand animal-health and the associated dramatic increase in human life expectancies. Indeed the possibility of eradicating infectious disease seemed feasible. However it soon became apparent that microorganisms wouldn't be defeated so easily. Their weapon: antibiotic resistance. Today microbial antibiotic resistance is rapidly exhausting our supply of effective compounds and making the possibility of a global public health disaster seems likely. The urgency of this situation has spawned a plethora of new multi-disciplinary research initiatives looking for novel antibiotics and other antimicrobial agents. In this timely book respected international experts summarize the most important research to provide a timely overview of the field. Essential reading!

\section{Table of Contents}

- Ch 1: What is an Antibiotic? Joan Wennstrom Bennett - Ch 2: Main Applications of Antibiotics. Biao Ren, Pei Huang, Jingyu Zhang, Wenni He, Jianying Han, Xueting Liu and Lixin Zhang • Ch 3: Microorganisms Producing Antibiotics. János Bérdy • Ch 4: The Need for New Antibiotics. Arnold L. Demain and Sergio Sánchez • Ch 5: Tackling Antibiotic Resistance. Jaroslav Spizek and Vladimir Havlicek • Ch 6: Eradication of Dormant Pathogens. Kim Lewis, Brian Conlon and Michael LaFleur • Ch 7: Toxicity of Antibacterial Drugs. Steven J. Projan • Ch 8: Overuse of Antibiotics: Non-medical Applications. Nelson Kardos • Ch 9: Antibiotics for Emerging and Re-emerging Diseases. Kazuro Shiomi and Satoshi Ōmura • Ch 10: Endophytes as a Potential Source of New Antibiotics. Silvia Guzmán-Trampe, Karol Rodríguez-Peña, Allan Espinosa-Gómez, Rosa E. Sánchez-Fernández, Martha L. Macías-Rubalcava, Luis B. Flores-Cotera and Sergio Sánchez - Ch 11: Antibiotics from Micro-organisms from Hot springs/Geysers. Girish B. Mahajan • Ch 12: New Sources of Antibiotics: Caves. Naowarat Cheeptham and Cesareo Saiz-Jimenez • Ch 13: Animal Venoms as Natural Sources of Antimicrobials.. R. Perumal Samy, S. Satyanarayanajois, O. L. Franco, B. G. Stiles and P. Gopalakrishnakone • Ch 14: New Targets for Antibacterial Compounds. Lynn L. Silver • Ch 15: Novel Antimicrobial and other Bioactive Metabolites Obtained from Silent Gene Clusters. Juan F. Martín and Paloma Liras • Ch 16: Combinatorial Biosynthesis for Antibiotic Discovery. Sung Ryeol Park and Yeo Joon Yoon • Ch 17: Lantibiotics and Other Antibacterial Peptides. Margherita Sosio and Stefano Donadio • Ch 18: Antiviral Compounds of Natural Origin. P. Veiga-Crespo, M. Viñas and Tomas Gonzalez Villa • Ch 19: New Compounds with Antibacterial Activity. P. Veiga-Crespo, A. Sánchez-Pérez, D. Piso and Tomas Gonzalez Villa • Ch 20: Use of Antibiotic Core Structures to Generate New and Useful Macrolide Antibiotics. Prabhavathi Fernandes • Ch 21: Antibiotics in the Pipeline. Hyunjun Park and Michael Thomas

More details at: www.horizonpress.com/antibiotics

\begin{tabular}{|c|c|}
\hline & Antifungals \\
\hline COMING & $\begin{array}{l}\text { From Genomics to Resistance and the Development of Novel Agents } \\
\text { Edited by: Alix T. Coste } \\
\text { 1/nstitute of Microbiology, University Hospital Lausanne,1011 Lausanne, Switzerland; } \\
\text { Pathogène, L'UNAM Université d'Angers, and Laboratoire de Parasitologie-Mycologie, Centre Hospitalier Universitaire, } \\
\text { Angers, France } \\
\text { C. } 340 \text { pp } \\
\text { Hardback: April 2015. ISBN 978-1-910190-01-2£159, } \$ 319 \\
\text { Ebook: March 2015. ISBN 978-1-910190-02-9£159, \$319 }\end{array}$ \\
\hline \multicolumn{2}{|c|}{$\begin{array}{l}\text { Topics } \\
\text { - Ch 1: Molecular Mechanisms of Resistance of Candida spp. to Membrane-targeting Antifungals. } \bullet \text { Ch 2: Point Mutations and Membrane-targeting } \\
\text { Antifungals Resistance in Aspergillus fumigatus and other non-Candida Species. } \bullet \text { Ch 3: Echinocandins: Resistance Mechanisms. } \bullet \text { Ch 4: Biofilms } \\
\text { and Antifungal Resistance. } \bullet \text { Ch 5: Drug Combinations as a Strategy to Potentiate Existing Antifungal Agents. } \bullet \text { Ch 6: Approaches to Detect } \\
\text { Alternative Mechanisms of Resistance to Systemic Antifungals. } \bullet \text { Ch 7: New Antifungal Discovery from Existing Chemical Compound Collections. } \\
\text { Ch 8: Exploring New Insights into Fungal Biology as Novel Antifungal Drug Targets. } \bullet \text { Ch 9: Strategies for the Identification of the Mode-of-action of } \\
\text { Antifungal Drug Candidates. } \bullet \text { Ch 10: Genome Integrity: Mechanisms and Contribution to Antifungal Resistance. } \bullet \text { Ch 11: Modulation of the Host } \\
\text { Response to Control Invasive Fungal Infections. } \bullet \text { Ch 12: Antifungal Vaccines and Immunotherapeutics. } \bullet \text { Ch 13: Animal Models to Study Fungal } \\
\text { Virulence and Antifungal Drugs. }\end{array}$} \\
\hline Full & izonpr \\
\hline
\end{tabular}




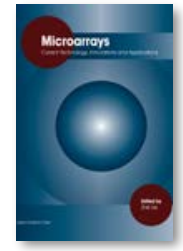

Microarrays

Current Technology, Innovations and Applications

Edited by:Zhili $\mathrm{He}$

c. 250 pp, August 2014

Hardback: ISBN 978-1-908230-49-2 £159/\$319

Ebook: ISBN 978-1-908230-59-1£159/\$319

Focused on current microarray technologies and their applications in environmental microbiology.

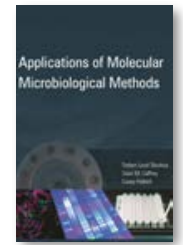

\section{Applications of Molecular Microbiological}

Methods

Edited by: TL Skovhus, SM Caffrey, CRJ Hubert

xii + 214 pp, March 2014

Hardback: ISBN 978-1-908230-31-7£159/\$319

Ebook: ISBN 978-1-908230-69-0 £159/\$319

Emerging molecular methods that allow the diversity of a microbial

community to be surveyed and its functions to be investigated.

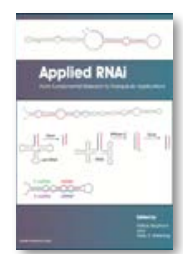

\section{Applied RNAi}

From Fundamental Research to Therapeutic Applications

Edited by: P Arbuthnot, MS Weinberg

$\mathrm{X}+252 \mathrm{pp}$, June 2014

Hardback: ISBN 978-1-908230-43-0 £159/\$319

Ebook: ISBN 978-1-908230-67-6 £159/\$319

RNAi experts critically review the most interesting advances in basic

applied RNAi research, highlight the applications in RNAi-based

therapies and discuss the technical hurdles that remain.

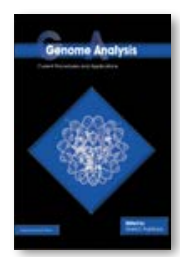

\section{Genome Analysis}

Current Procedures and Applications

Edited by: MS Poptsova

xiv + 374 pp, January 2014

Hardback: ISBN 978-1-908230-29-4 £159/\$319

Ebook: ISBN 978-1-908230-68-3 £159/\$319

An up-to-date and comprehensive overview of next-generation

sequencing data analysis, highlighting problems and limitations,

applications and developing trends in various fields of genome research.

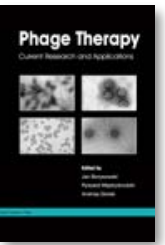

\section{Phage Therapy}

Current Research and Applications

Edited by: J Borysowski, R Międzybrodzki, A Górski

$\mathrm{xvi}+378 \mathrm{pp}$, April 2014

Hardback: ISBN 978-1-908230-40-9 £180/\$360

Ebook: ISBN 978-1-908230-74-4 £180/\$360

Full and comprehensive coverage of phage therapy with a focus on

current research and emerging applications.

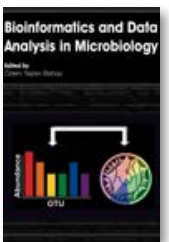

Bioinformatics and Data Analysis in

Microbiology

Edited by: Ö Taştan Bishop

X 248 pp, April 2014

Hardback: ISBN 978-1-908230-39-3 £159/\$319

Ebook: ISBN 978-1-908230-73-7 £159/\$319

Invaluable, up-to-date and detailed information on various aspects of

bioinformatics data analysis with applications to microbiology.

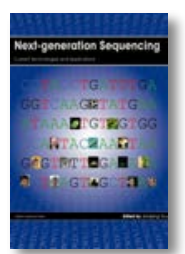

Next-generation Sequencing

Current Technologies and Applications

Edited by: J Xu

xii + 160 pp, March 2014

Hardback: ISBN 978-1-908230-33-1 £120/\$240

Ebook: ISBN 978-1-908230-95-9 £120/\$240

The most recent advances in NGS instrumentation and data

analysis, current NGS platforms, sequencing chemistries, instrument specifications, general workflows and procedures.

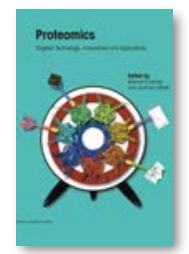

Proteomics

Targeted Technology, Innovations and Applications

Edited by: M Fuentes, J LaBaer

x + 186 pp, September 2014

Hardback: ISBN 978-1-908230-46-1£159/\$319

Ebook: ISBN 978-1-908230-62-1£159/\$319

An overview of targeted proteomics in biomedical science.
New For 2015

\section{Probiotics and Prebiotics}

Current Research and Future Trends

Edited by: Koen Venema and Ana Paula do Carmo

Summer 2015

Written by leading international researchers, each of the 33 chapters affords a critical insight to a particular topic, reviews current research, discusses future direction and aims to stimulate discussion. Topics range from the organisms (Lactobacilli,

bifidobacteria, yeast, etc) and techniques and approaches used (metagenomics, etc) to

the reviews of the clinical and medical aspects. Essential Reading.

\section{- Emerging Trends in Antibacterial Discovery ISBN: 978-1-904455-89-9}

"essential reference for anyone interested in antibiotic resistance or discovery" (Microbiol Today)

- Vaccine Design

ISBN: 978-1-904455-74-5

"essential reading" (Arch. Virol.)

- Pathogenic Neisseria

ISBN: 978-1-908230-47-8/978-1-908230-61-4

- Oral Microbial Ecology

ISBN: ISBN 978-1-908230-17-1/978-1-908230-82-9

"essential text" (Beneficial Microbes.)

- Campylobacter Ecology and Evolution ISBN: 978-1-908230-36-2/978-1-908230-98-0

- Pathogenic Escherichia coli

ISBN: 978-1-908230-37-9/978-1-908230-99-7

"current, comprehensive, and a great resource" (JAVMA)

\section{- Bacterial Toxins}

ISBN: 978-1-908230-28-7/978-1-908230-70-6

"packed full of detailed information" (Biospektrum)

- Bacterial Membranes

SBN: 978-1-908230-27-0/978-1-908230-91-1

"I highly recommend this book" (Biospektrum)

- Horizontal Gene Transfer in Microorganisms ISBN: 978-1-908230-10-2/978-1-908230-72-0

"state of the art information ... up-to-date" (Int. Micro.)

- Microbial Biofilms

ISBN: 978-1-904455-96-7

"a useful update" (Micro. Today)

New For 2015

\section{Advanced Vaccine Research Methods for the} Decade of Vaccines

Edited by: Fabio Bagnoli and Rino Rappuoli

c. 550 pp, March 2015

Hardback: $978-1-910190-03-6, £ 180 / \$ 360$

Ebook: ISBN 978-1-910190-04-3, £180/\$360

Topics covered include: the use of deep sequencing, cellular screens to interrogate the human $T$ and $B$ cell repertoires, comparative genomics to track bacterial pathogens, quantitative proteomics, structural biology, novel strategies for vaccine administration, T-cell inducing vaccines, etc, etc. A valuable resource. 